\title{
FEASIBILITY STUDY PROGRAM ZAKAT COMMUNITY DEVELOPMENT STUDI KASUS: DESA MEKARSARI, KABUPATEN GARUT
}

\author{
Elis Nurhasanah \\ Universitas Siliwangi Tasikmalaya, Indonesia \\ Email: elis.nurhasanah@unsil.ac.id
}

\begin{abstract}
Feasibility Study of Zakat Community Development Programs Case Study: Mekarsari, Garut. This paper assessed the feasibility of community-based zakat (zakat community development) recipients and proposing relevant empowerment programs to alleviate mustahiq community conditions in Mekarsari Village, Garut District. Assessment tool used in this research adopted by Puskas BAZNAS was Zakat Village Index (IDZ). Result showed that Mekarsari Village reached 0.55, with the score of economic dimension index reached 0.39, 0.54 for the health dimension, 0.64 for the education deimension, social and humanitarian dimension and da'wah dimension are 0.55, 0.68 respectively. Thus, Mekarsari Village in Garut District cauld be considered for assistance by zakat fund based on calculation of IDZ. The empowerment program relevant to the condition of the mustahiq community in Garut District was community economic improvement through empowerment of economic potential owned based on consideration of the value of the economic dimension had the lowest value of the five IDZ variable.
\end{abstract}

Keywords: Feasibility study, Zakat Community Development, Zakat Village Index

\begin{abstract}
Abstrak. Feasibility Study Program Zakat Community Development Studi Kasus: Desa Mekarsari, Kabupaten Garut. Artikel ini bertujuan mengukur kelayakan mustahik berbasis komunitas (Zakat community development) dan mengusulkan program pemberdayaan yang relevan untuk mengurangi kondisi komunitas mustahik di Desa Mekarsari, Kabupaten Garut. Alat ukur yang digunakan dalam penelitian ini diadopsi dari Puskas BAZNAS yaitu Indeks Desa Zakat. Hasil menunjukan bahwa Desa Mekarsari memiliki nilai IDZ 0.55, dengan nilai dimensi ekonomi 0.39, 0.54 nilai dimensi kesehatan, 0.64 nilai dimensi pendidikan, dimensi sosial dan kemanusiaan serta dakwah masing masing dengan nilai 0.55, 0.68. Dengan demikian, Desa Mekarsari di Kabupaten Garut dapat dipertimbangakan utnutk dibantu oleh dana zakat berdasarkan hasil perhitungan IDZ. Program yang relevan dengan kondisi komunitas mustahik di Desa mekarsari adalah meningkatkan ekonomi komunitas melalui pemberdayaan potensi ekonomi yang dimiliki berdasar pada pertimbangan nilai dimensi ekonomi yang memiliki nilai terendah dari kelima variabel IDZ.
\end{abstract}

Kata Kunci: Feasibility Study, Zakat Community Development, Indeks Desa Zakat. 


\section{INTRODUCTION}

Merujuk data BPS Jawa Barat, tingkat kemiskinan yang terjadi di Provinsi Jawa Barat masih didominasi oleh tingginya persentase kemiskinan di pedesaan. Persentase kemiskinan di perdesaan pada tahun 2017 mencapai 10,77\%, sedangkan di perkotaan 6,76\%, perbedaannya mencapai 4,01\%. Tidak hanya terjadi tahun 2017 saja, dalam lima tahun terakhir, pedesaan masih mendominasi tingkat kemiskinan di Provinsi Jawa Barat. Meskipun pada tahun 2017 mengalami penurunan 0,95\% dari tahun sebelumnya, belum signifikan, oleh karena tingkat kemiskinan masih fluktuatif. Sehingga dapat dikatakan pedesaan merupakan sarang kemisikinan. Hal tersebut dapat kita lihat dari pada grafik berikut:

\section{Grafik. 1.3 Persentase Kemiskinan Pedesaan dan Perkotaan}

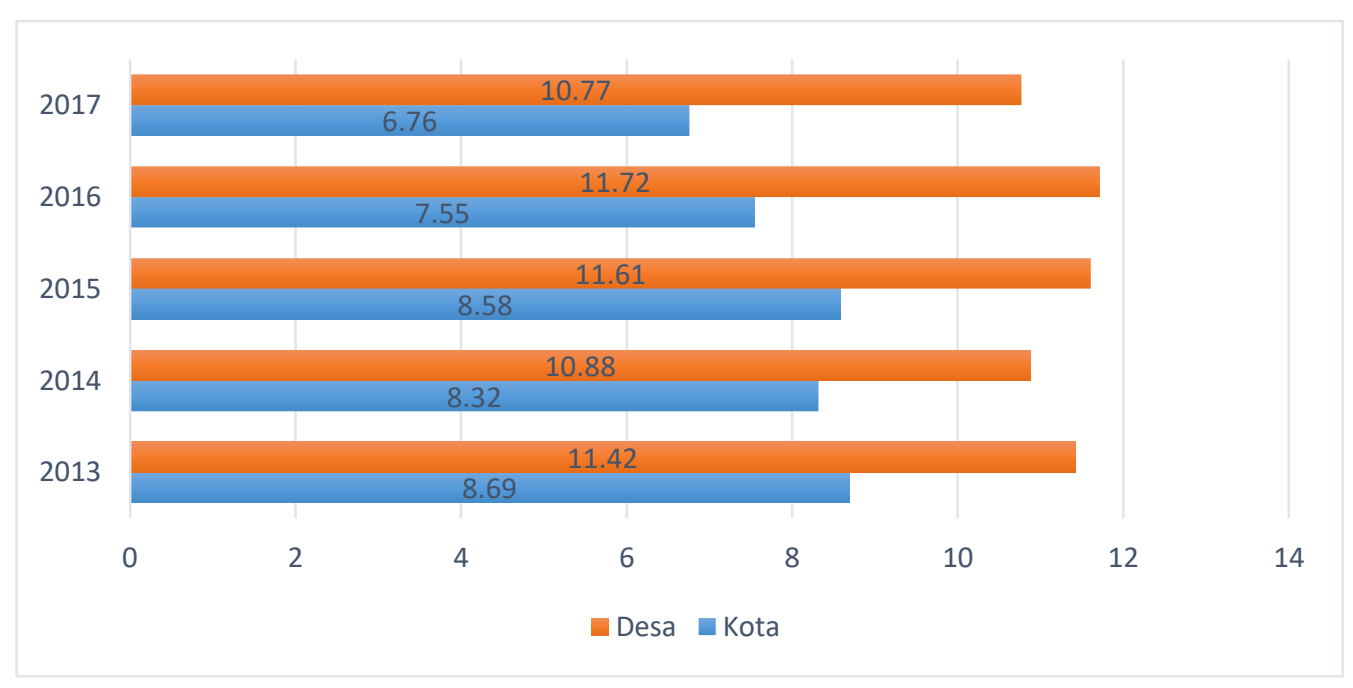

Sumber: www.jabar.bps.go.id

Instrumen sosial Islam yang berperan mengurangi kemiskinan dan menjamin kesejahteraan umat adalah zakat, infak dan sedekah serta wakaf. Hal tersebut sebagaimana dikemukakan oleh Sadeq (2002). Menurut Sadeq (2002:137), Islam memiliki beberapa instrumen charity dalam mengetaskan kemiskinan dan membaginya kedalam tiga bagian diantaranya:

a. Charity yang bersifat wajib yaitu zakat fitrah dan zakat

b. Charity yang bersifat sunat yaitu infaq dan sedekah. 
Elis Nurhasanah: Feasibility Study Program...

c. Charity yang bersifat abadi yaitu wakaf.

Berkaitan dengan kemiskinan di pedesaan Baznas sebagai lembaga zakat nasional memiliki suatu program yang dinamakan zakat community development, program yang secara khusus mendayagunakan dana zakat berbasis pemberdayaan berbasis komunitas. Beberapa penelitian sebelumnya program zakat community development memiliki peran dalam mengentaskan kemiskinan dan meningkatkan kesejahteraan para mustahik. Seperti penelitian Beik dan Pratama (2016), Beik dan Arsyanti (2016), Utami dan Lubis (2014), Sumantri (2016), Aan (2015) dan penelitian lainnya.

Peran zakat produktif terhadap penurunan kemiskinan dinyatakan dalam penelitian Beik dan Pratama (Beik dan Pratama 2016), menyatakan bahwa program zakat produktif memberikan pengaruh signifikan terhadap peningkatan indeks kesejahteraan mustahik. Senada dengan penelitian Beik dan Arsyanti (Beik dan Arsyanti 2016) yaitu bahwa dengan adanya program zakat produktif dompet dhuafa berhasil menurunkan indeks kemiskinan material dan spiritual rumah tangga mustahik.

Penelitian lain menyatakan bahwa pendapatan mustahik setelah menerima dana zakat produktif meningkat dibanding sebelum menerima zakat produktif (Utami dan Lubis 2014), begitu juga Sumantri R. (Sumantri 2016) menyatakan bahwa program zakat community development memberikan pengaruh yang cukup baik. Nurzaman (Nurzaman 2016) Indeks pendapatan dan indeks pendidikan penerima zakat (mustahik) secara statistik lebih besar dibanding IPM nonmustahik. IPM rumah tangga mustahik lebih besar daripada IPM bukan mustahik.

Keberhasilan program zakat produktif dalam mengurangi kemiskinan terutama kemiskinan dipedesaan, tidak terlepas dari asesmen awal yang dilakukan oleh organisasi pengelola zakat. Program apa yang sesuai dengan potensi dan kebutuhan komunitas mustahik. Sehingga program tersebut mampu memberikan perubahan yang signifikan terhadap tingkat kesejahteraan komunitas yang akan dibantu oleh program zakat community development.

Penelitian usulan program pernah dilakukan oleh Khairunnajah, dkk ( khairunnajah, Beik dan Sartono 2019) di Desa Cemplang, Bogor. Hasil menunjukan bahwa Desa Cemplang dapat dipertimbangkan untuk dibantu oleh dana zakat melalui 
program pengembangan produk lokal berbasis komoditas agrikultur. Adapun Farikhatusholikhah, dkk (Farikhatusholikhah, Novianti, dan Ali 2018) hasil asesmen menunjukan bahwa Desa Bedono Kabupaten Demak, dapat dipertimbangkan dibantu oleh dana zakat dengan nilai IDZ 0.49.

Dengan demikian, pengukuran kelayakan dan usulan program untuk Desa Mekarsari sebagai calon penerima program zakat community development penting dilakukan asesmen oleh lembaga zakat. Dengan tujuan mempertimbangkan layak atau tidaknya dibantu dana zakat dan merekomendasikan program apa yang dibutuhkan jika komunitas mustahik desa mekarsari dipertimbangkan untuk dibantu oleh program zakat community development.

Penelitian ini menggunakan metode campuran (mixed method) yaitu menggunakan pendekatan kuantitatif dan kualitatif. Data primer diperoleh dari interview dan observasi, sedangkan data sekunder diperoleh dari literatur review seperti dokumen-dokumen, buku dan jurnal. Instrumen analisis yang digunakan untuk mengukur kelayakan dan usulan program pemberdayaan zakat community development adalah Indeks Desa Zakat (IDZ). IDZ memiliki lima variabel dimensi yaitu dimensi ekonomi, dimensi kesehatan, dimensi pendidikan, dimensi sosial dan kemanusiaan dan dimensi dakwah. Data yang telah dikumpulkan dikalkulasikan ke dalam sistem dashboard Indeks Desa Zakat. Perhitungan IDZ menggunakan metode multi-stage weighted index. Formula perhitungannya adalah:

Puskas, (2017: 9-11) menentukam prosedur dan formula perhitungan IDZ yaitu sebagai berikut;

Pertama, kriteria penilaian masing-masing indikator menggunakan skala likert yang terdiri dari 5 kriteria penilaian. semakin tinggi nilainya, maka desa tersebut dianggap semakin tidak diprioritaskan untuk dibantu. Setelah didapatkan angka aktual (berdasarkan fakta, temuan dan data yang diperoleh), maka indikator dihitung dengan menggunakan metode perhitungan sebagai berikut:

$$
\text { Indikator }_{x}=\frac{\text { Skor }_{x}-S k o r_{\min }}{S k o r_{\max }-S k o r_{\min }}
$$

Dimana,

Indikator $_{\mathrm{x}}=$ nilai Indikator $\mathrm{x}$ 
Elis Nurhasanah: Feasibility Study Program...

$$
\begin{aligned}
& \text { Skor }_{\mathrm{x}}=\text { skor pada indikator } \mathrm{x} \\
& \text { Skor }_{\text {min }}=1 \text { (nilai paling kecil) } \\
& \text { Skor }_{\text {max }}=5 \text { (nilai paling besar) }
\end{aligned}
$$

Kedua, untuk mendapatkan indeks indikator adalah dengan mengkalikan nilai indikator, dengan bobot-botot nilai indikator.

Ketiga, indeks indikator dikelompokan sesuai dengan indikator variabelnya, dan dikali dengan bobot masing-masing indikator variabel untu mendapatkan nilai indeks variabel.

Keempat, indeks variabel dikalikan dengan bobot masing-masing dimensi untuk mendapatkan indeks dimensi. Hasilnya merupakan indeks komposit Indeks Desa Zakat. Rumusnya adalah sebagai berikut:

$$
I D Z=\frac{X 1_{e k}+X 2_{k s}+X 3_{p e}+X 4_{k e}+X 5_{d a}}{5}
$$

Dimana

$$
\begin{aligned}
& \text { IDZ = Indeks Desa Zakat } \\
& \mathrm{X} 1, \ldots \mathrm{X} 5 \text { = Bobot penilaian } \\
& \mathrm{Ek}=\text { Dimensi Ekonomi } \\
& \mathrm{Pe}=\text { Dimensi Pendidikan } \\
& \mathrm{Ks}=\text { Dimensi Kesehatan } \\
& \mathrm{Ke}=\text { Dimensi Sosial dan Kemanusiaan } \\
& \mathrm{Da}=\text { Dimensi Dakwah }
\end{aligned}
$$

Jika hasil perhitungan IDZ mendekati nilai 1 maka program pendayagunaan zakat efektif terhadap kesejahteraan masyarakat, dan tidak diprioritaskan untuk dibantu dana zakat.

\section{PEMBAHASAN}

\section{Study Kelayakan}

Dikalangan masyarkat yang bergelut dibidang usaha dan bisnis, studi kelayakan atau dikenal dengan feasibility study merupakan hal yang tidak asing lagi. Feasibility study merupakan bahan pertimbangan dalam mengambil suatu keputusan, apakah 
menerima suatu gagasan usaha atau proyek yang direncanakan atau menolaknya (Purnomo, Riawan dan Sugianto 2017). Layak atau tidaknya berdasarkan pertimbangan dari manfaat yang diberikan baik yang bersifat financial benefit maupun dalam arti social benefit.

Jebrin (2017:3) mendefinisikan:

"The feasibility study as a tool that can provide a technical, economic and financial justification of a decision to finance an investment project. The feasibility study is a critical step in the business assessment process. The feasibility study aims to provide decision makers with comprehensive projectspecific information to decide if the economic returns of the project.

Artinya bahwa studi kelayakan merupakan alat justifikasi teknik, ekonomi dan keuangan dari sebuah keputusan untuk membiayai projek investasi. Studi kelayakan juga merupakan langkah kritis dalam proses pengukuran suatu bisnis. Tujuannya untuk memudahkan pembuat keputusan memperoleh informasi yang sepesifik dan komprehensif mengenai keputusan pengembalian proyek ekonomi.

Studi kelayakan bisnis dapat didefinisikan sebagai controlled process untuk mengidentifikasi masalah, menentukan hasil yang sukses, dan menilai kisaran biaya dan manfaat yang terkait dengan beberapa alternatif untuk memecahkan masalah dalam menentukan apakah ide proyek itu layak atau tidak.

Adapun studi kelayakan pada program zakat community development adalah suatu alat untuk mengukur kondisi ekonomi, kesehatan, pendidikan, sosial dan kemanusiaan serta dimensi dakwah yang ada di suatu komunitas atau desa. Tujuannya adalah agar pembuat keputusan yaitu lembaga zakat mudah dalam mendistribusikan dan mendayagunakan dana zakat yang dikelolanya, tidak salah sasaran, efektif dan efisien. Apakah program yang disalurkan dapat memecahkan masalah yang dimiliki komunitas tersebut atau tidak. Dengan kata lain apakah dosis yang diberikan sesuai dengan kondisi pasien yang dalam hal ini adalah komunitas mustahik. Dengan demikian pendistribusian dana zakat sesuai dengan tujuan utama dari program zakat community development. 
Elis Nurhasanah: Feasibility Study Program...

\section{Zakat Community Development}

Zakat berbasis komunitas atau BAZNAS menyebutnya dengan istilah zakat community development merupakan pengintegrasian program-program yang bersumber dari dana Zakat Infak dan Shadaqoh untuk mengatasi masalah kesehatan, pendidikan, ekonomi dan masalah sosial dengan menggunakan pendekatan komunitas, pendekatan kewilayahan dan pendekatan wilayah sasaran program. Pendekatan komunitas yaitu pendekatan kelompok masyarakat yang terorganisir dan memiliki kesamaan aktifitas sedangkan pendekatan kewilayahan merupakan pendekatan lokasi sebagai sasaran program dengan permasalahan secara geografis dan kependudukan serta pendekatan wilayah sasaran program sesuai dengan kondisi masyarakat apakah perkotaan, perdesaan, pegunungan atau pesisir yang jelas membutuhkan penanganan yang berbeda.

Zakat community development (ZCD) merupakan upaya untuk mendesain pemberdayaan masyarakat melalui zakat atau memaksimalkan potensi zakat untuk pemberdayaan dan pengembangan umat (Kemenag RI Dirjen Bimbingan Masyarakat Islam Direktorat Pemberdayaan Zakat; hal. 85). Tujuan ZCD adalah merubah mindset masyarakat dari zakat sebagai pemenuhan kewajiban menjadi zakat sebagai kebutuhan untuk pemberdayaan dan pengembangan diri yang mengantarkan pada perubahan kondisi diri dan lingkungan.

ZCD memiliki arah dan strategi untuk melakukan pemberdayaan masyarkat dalam memahami, menggali dan mendayagunakan potensi serta kapasitas diri untuk keluar dari siklus kemiskinan. Maksud dari zakat berbasis komunitas adalah menjadikan komunitas dan desa sebagai penerima program zakat yang bersifat produktif dengan mengembangkan potensi yang dimiliki oleh komunitas atau desa secara komprehensif yang sumber pendanaannya dari zakat, infak, sedekah dan dana sosial keagamaan lainnya.

Lima prinsip BAZNAS yang ditekankan dalam kegiatan zakat community development, diantaranya:

1. Prinsip profit yaitu kegiatan ZCD memberikan nilai keuntungan atau profit baik material maupun non material bagi pemberdayaan masyarakat. 
2. Prinsip kontinuitas yaitu program bersifat jangka panjang dengan target kemandirian masyarakat.

3. Prinsip multiplier efek yaitu program memiliki efek multiganda terhadap aspek kehidupan masyarakat dan saling keterkaitan.

4. Prinsip partisipatory yaitu melibatkan langsung pada aktifitas individu dan masyarakat mulai dari tahap perencanaan sampai pelaksanaan baik individu maupun masyarakat terlibat sebagai subjek (pelaku), dengan melibatkan pendamping.

5. Zakat Infak Sedekah sebagai sumber dana stimulan dalam membantu pemenuhan kebutuhan atau masalah yang dihadapi masyarakat.

\section{Indeks Desa Zakat}

Indeks Desa Zakat (IDZ) merupakan sebuah instrumen zakat nasional yang berfungsi sebagai alat untuk mengasesmen kelayakan, memonitoring, dan mengevaluasi program zakat berbasis komunitas (Puskas BAZNAS, 2017). Secara umum komponen IDZ ada lima yaitu dimensi ekonomi, dimensi pendidikan, imensi kesehatan, dimensi sosial kemanusiaan dan dimensi dakwah. Pembeda IDZ dengan indeks lainnya seperti Indeks Desa Membangun adalah dalam IDZ menjadikan unsur Religiusitas sebagai bagian dari unsur penilaian.

IDZ bermanfaat bagi organisasi pengelola zakat dalam melakukan pendistribusian dana zakat dalam bentuk program pemberdayaan berbasis komunitas atau desa. Sehingga program pemberdayaan berbasis komunitas atau desa terukur, termonitor dan terevaluasi mulai dari pengukuran, perencanaan, pelaksanaan dan evaluasi program.

\section{Hasil dan Pembahasan}

Asesmen kelayakan Desa Mekarsari Kabupaten Garut menjadi mustahik program zakat community development dilakukan menggunakan Indeks Desa Zakat. Hasil pengukuran IDZ menunjukan bahwa nilai indeks desa zakat Desa Mekarsari adalah 0.55. Artinya hasil pengukuran menunjukan bahwa Desa Mekarsari Kabupaten Garut dapat dipertimbangkan untuk dibantu dana zakat. Berikut ini grafik nilai setiap dimensi Desa Mekarsari, Kabupaten Garut: 


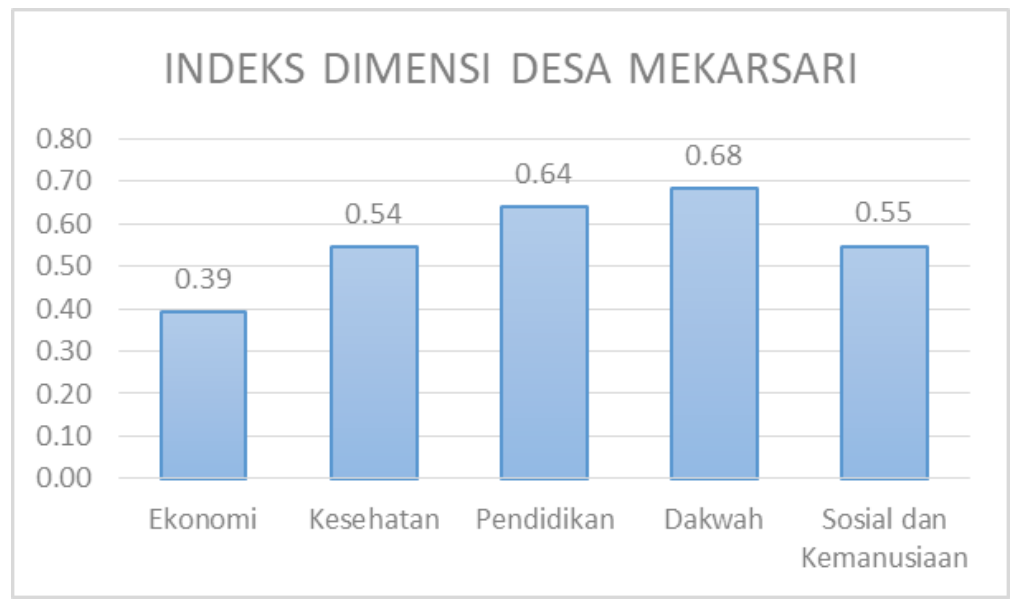

Sumber: Data Primer Diolah (2018)

Berdasarkan grafik di atas rentang nilai IDZ Desa Mekarsari Kabupaten Garut berada direntang 0,41-0,60 yang artinya cukup baik, dengan interpretasi Desa Mekarsari dapat dipertimbangkan untuk dibantu. Selain dari nilai indeks, faktorfaktor yang mempengaruhi rendahnya nilai IDZ Desa Mekarsari dipengaruhi oleh variabel masing-masing indeks dimensi. Berikut hasil masing-masing dimensi, variabel dan indikator masing-masing indeks dimensi:

\section{Dimensi Ekonomi}

Hasil indeks dimensi ekonomi adalah 0,39 artinya kondisi dimensi ekonomi Desa Mekarsari Kabupaten Garut kurang baik dengan demikian dapat diinterpretasikan bahwa Desa Mekarsari dapat diprioritaskan untuk dibantu oleh dana zakat pada dimensi ekonomi. Nilai indeks dimensi, indeks variabel dan indikator indeks dapat dilihat pada tabel dibawah ini:

Tabel 1.1 Dimensi, Variable dan Indikator Indeks Dimensi Ekonomi

\begin{tabular}{|c|c|c|c|c|}
\hline \multirow{2}{*}{$\begin{array}{c}\text { Index } \\
\text { Dimensi }\end{array}$} & Variabel & $\begin{array}{c}\text { Index } \\
\text { Variabel }\end{array}$ & Indikator & $\begin{array}{c}\text { Index } \\
\text { Indikator }\end{array}$ \\
\hline \multirow{2}{*}{$\mathbf{0 , 3 9}$} & Kegiatan Ekonomi Produktif & $\mathbf{0 , 3 4}$ & $\begin{array}{c}\text { Tingkat Partisipasi Angkatan } \\
\text { Kerja }\end{array}$ & $\mathbf{0 , 5}$ \\
\cline { 4 - 5 } & & & $\begin{array}{c}\text { Jumlah Komunitas Penggiat } \\
\text { Industri Kreatif }\end{array}$ & $\mathbf{0 , 0 0}$ \\
\cline { 3 - 5 } & Pusat Perdagangan Desa & $\mathbf{0 , 1 2}$ & Pasar & $\mathbf{0 , 0 0}$ \\
\hline
\end{tabular}


Islamiconomic: Jurnal Ekonomi Islam Vol.10 No.2 Juli - Desember 2019

\begin{tabular}{|c|c|c|c|}
\hline & & Pusat Perdagangan & 0,25 \\
\hline \multirow{3}{*}{$\begin{array}{c}\text { Akses Transportasi dan Jasa } \\
\text { Logistik/Pengiriman }\end{array}$} & \multirow{3}{*}{0,87} & Aksesibilitas Jalan Desa & 1,00 \\
\hline & & Moda Transportasi Umum & 1,00 \\
\hline & & $\begin{array}{c}\text { Jasa Logistik / Pengiriman } \\
\text { Barang }\end{array}$ & 0,50 \\
\hline \multirow{3}{*}{ Akses Lembaga Keuangan } & \multirow{3}{*}{$\mathbf{0 , 3 0}$} & $\begin{array}{c}\text { Ketersediaan dan } \\
\text { Aksesibilitas Lembaga } \\
\text { Keuangan }\end{array}$ & $\mathbf{0 , 0 0}$ \\
\hline & & $\begin{array}{l}\text { Persentase penduduk yang } \\
\text { berhutang pada rentenir }\end{array}$ & 0,75 \\
\hline & & $\begin{array}{c}\text { Persentase penduduk } \\
\text { menggunakan } \\
\text { produk/layanan jasa } \\
\text { keuangan }\end{array}$ & 0,25 \\
\hline
\end{tabular}

Sumber: Data Primer Diolah (2018)

Tabel 1.1 menunjukan bahwa kondisi ekonomi Desa Mekarsari kurang baik. Hal tersebut dapat dilhat dari rendahnya nilai indeks variabel kegiatan ekonomi produktif $(0,34)$, pusat perdagangan desa $(0,12)$ dan akses lembaga keuangan $(0,30)$. variabel yang menonjol adalah akses transportasi dan jasa logistik/pengiriman $(0,87)$. Rendah atau tingginya niali indeks variabel dipengaruhi olej nilai indeks indikator. Variabel kegiatan ekonomi produktif memiliki nilai indeks indikator $(0,00)$ pada indikator jumlah komunitas pegiat industri produktif. Artinya perlu digiatan pegiat industri ekonomi kreatif di Desa Mekarsari. Selain itu, indikator ketersediaan pasar $(0,00)$ pun berpengaruh terhadap rendahnya nilai indeks variabel pusat perdagangan desa, dan nilai indikator ketersediaan dan aksestabilitas lembaga keuangan yang memiliki nilai $(0,00)$ menjadi pengaruh terhadap rendahnya indeks dimensi ekonomi.

Nilai variabel akses transportasi dan jasa logistik yang baik yaitu 0,87 menjadi kelebihan yang harus dimanfaatkan oleh Desa Mekarsari. Dengan demikian, program bantuan dana zakat yang diusulkan untuk Desa Mekarsari adalah pengembangan potensi produk unggulan yang dimiliki yaitu agrikultur dan pembinaan terhadap pegiat ekonomi kreatif yang belum terkelola oleh pemerintahan desa.

\section{Dimensi Kesehatan}

Hasil Indeks Demensi Kesehatan Desa Mekarsari Cukup baik (0,54) sehingga dapat diiinterpretasikan bahwa Desa Mekarsari dapat dipertimbangkan untuk 
Elis Nurhasanah: Feasibility Study Program...

dibantu dana zakat. Adapun nilai varibel dan indikator indek kesehatan dapat dilihat pada tabel 1.2 dibawah ini:

Tabel 1.2 Dimensi, Variable dan Indikator Indeks Dimensi Kesehatan

\begin{tabular}{|c|c|c|c|c|c|}
\hline Dimensi & $\begin{array}{c}\text { Index } \\
\text { Dimensi }\end{array}$ & Variabel & $\begin{array}{c}\text { Index } \\
\text { Variabel }\end{array}$ & Indikator & $\begin{array}{c}\text { Index } \\
\text { Indikator }\end{array}$ \\
\hline \multirow{10}{*}{ Kesehatan } & \multirow{10}{*}{0,54} & \multirow{4}{*}{$\begin{array}{l}\text { Kesehatan } \\
\text { Masyarakat }\end{array}$} & \multirow{4}{*}{0,69} & Fasilitas Air Bersih & 0,75 \\
\hline & & & & $\begin{array}{l}\text { Jumlah Rumah Memiliki } \\
\text { Kamar Mandi dan Jamban }\end{array}$ & 0,50 \\
\hline & & & & $\begin{array}{l}\text { Jumlah Rumah Memiliki Akses } \\
\text { Air Minum }\end{array}$ & 0,75 \\
\hline & & & & Kondisi Rumah Penduduk & 0,75 \\
\hline & & \multirow{5}{*}{$\begin{array}{l}\text { Pelayanan } \\
\text { Kesehatan }\end{array}$} & \multirow{5}{*}{0,56} & Tersedia Sarana Puskesmas & 0,75 \\
\hline & & & & Tersedia Sarana Polindes & 0,00 \\
\hline & & & & Tersedia Bidan & $\mathbf{0 , 0 0}$ \\
\hline & & & & Tersedia Sarana Posyandu & $\mathbf{0 , 5 0}$ \\
\hline & & & & $\begin{array}{l}\text { Ketersediaan Dokter/Bidan } \\
\text { Bersertifikat }\end{array}$ & 1,00 \\
\hline & & $\begin{array}{l}\text { Jaminan } \\
\text { Kesehatan }\end{array}$ & 0,25 & $\begin{array}{c}\text { Jumlah Penduduk Desa yang } \\
\text { Telah Memiliki BPJS } \\
\text { Kesehatan }\end{array}$ & 0,25 \\
\hline
\end{tabular}

Sumber: Data Primer Diolah (2018)

Berdasarkan tabel 1.2, menunjukan bahwa jaminan kesehatan warga Desa Mekarsari buruk $(0,25)$, tidak adanya sarana polindes $(0,00)$ dan hanya 1 bidan tersertifikasi sehingga nilai indikator tersedia bidan $(0,00)$. Kesehatan masyarakat Desa Mekarsari sudah baik, namun ketersediaan kamar mandi dan jamban masih kurang (0,50), dimana kepemilikan kamar mandi di dalam baru 50\% sisanya kepemilikan kamar mandi di luar rumah.

\section{Dimensi Pendidikan}

Hasil indeks dimensi pendidikan Desa Mekarsari baik $(0,64)$ sehingga dapat diinterpretasikan bahwa Desa Mekarsari kurang diprioritaskan untuk dibantu dalam dimensi Pendidikan oleh dana zakat. Berikut nilai dimensi, variabel dan indikator dimensi pendidikan Desa Mekarsari:

Tabel 1.3 Dimensi, Variable dan Indikator Indeks Dimensi Pendidikan

\begin{tabular}{|c|c|c|c|c|c|}
\hline Dimensi & $\begin{array}{l}\text { Index } \\
\text { Dimensi }\end{array}$ & Variabel & $\begin{array}{l}\text { Index } \\
\text { Variabel }\end{array}$ & Indikator & $\begin{array}{l}\text { Index } \\
\text { Indikator }\end{array}$ \\
\hline Pendidik & & Tingkat Pendidikan & 0,52 & Tingkat $\quad$ Pendidikan & $\mathbf{0}$ \\
\hline
\end{tabular}


Islamiconomic: Jurnal Ekonomi Islam Vol.10 No.2 Juli - Desember 2019

\begin{tabular}{|c|c|c|c|c|}
\hline \multirow[t]{5}{*}{ an } & \multirow[t]{2}{*}{ dan Literasi } & & Penduduk Desa & \\
\hline & & & $\begin{array}{l}\text { Masyarakat dapat } \\
\text { Membaca dan Menghitung }\end{array}$ & 1 \\
\hline & & & $\begin{array}{l}\text { Ketersediaan Sarana dan } \\
\text { Prasarana Belajar }\end{array}$ & 1,00 \\
\hline & $\begin{array}{l}\text { Fasilitas } \\
\text { Pendidikan }\end{array}$ & 0,76 & $\begin{array}{l}\text { Akses ke Sekolah } \\
\text { Terjangkau dan Mudah }\end{array}$ & 1,00 \\
\hline & & & $\begin{array}{l}\text { Ketersediaan Jumlah Guru } \\
\text { yang Memadai }\end{array}$ & 0,25 \\
\hline
\end{tabular}

Sumber: Data Primer Diolah (2018)

\section{Dimensi Sosial dan Kemanusiaan}

Hasil dimensi sosial dan kemanusian Desa Mekarsari cukup baik dan dapat diinterpretasikan Desa Mekarsari dapat dipertimbangkan untuk dibantu oleh dana zakat pada dimensi sosial dan kemanusiaan $(0,55)$. Berikut rincian nilai masingmasing variabel pada tabel 1.4:

Tabel 1.4 Dimensi, Variable dan Indikator Indeks Dimensi Sosial dan Kemanusiaan

\begin{tabular}{|c|c|c|c|c|c|}
\hline Dimensi & $\begin{array}{c}\text { Index } \\
\text { Dimensi }\end{array}$ & Variabel & $\begin{array}{c}\text { Index } \\
\text { Variabel }\end{array}$ & Indikator & $\begin{array}{c}\text { Index } \\
\text { Indikator }\end{array}$ \\
\hline \multirow{7}{*}{$\begin{array}{l}\text { Sosial dan } \\
\text { Kemanusi } \\
\text { aan }\end{array}$} & \multirow{7}{*}{0,55} & \multirow{2}{*}{$\begin{array}{c}\text { Sarana Ruang } \\
\text { Interaksi Terbuka } \\
\text { Masyarakat }\end{array}$} & \multirow{2}{*}{0,64} & $\begin{array}{c}\text { Ketersediaan Sarana } \\
\text { Olah Raga }\end{array}$ & 0,5 \\
\hline & & & & $\begin{array}{c}\text { Terdapat Kelompok } \\
\text { Kegiatan Warga }\end{array}$ & 0,75 \\
\hline & & \multirow{4}{*}{$\begin{array}{c}\text { Infrastruktur } \\
\text { Listrik, Komunikasi } \\
\text { dan Informasi }\end{array}$} & \multirow{4}{*}{0,74} & $\begin{array}{c}\text { Ketersediaan Aliran } \\
\text { Listrik }\end{array}$ & 0,75 \\
\hline & & & & $\begin{array}{c}\text { Terdapat Akses } \\
\text { Komunikasi }\end{array}$ & 0,50 \\
\hline & & & & $\begin{array}{c}\text { Terdapat Akses } \\
\text { Internet }\end{array}$ & 0,75 \\
\hline & & & & $\begin{array}{c}\text { Terdapat Siaran TV } \\
\text { atau Radio }\end{array}$ & 1,00 \\
\hline & & $\begin{array}{c}\text { Mitigasi Bencana } \\
\text { Alam }\end{array}$ & 0,00 & $\begin{array}{c}\text { Penanggulangan } \\
\text { Bencana }\end{array}$ & 0,00 \\
\hline
\end{tabular}

Sumber: Data Primer Diolah (2018) 
Elis Nurhasanah: Feasibility Study Program...

Tabel 1.4 menunjukan terjadi masalah pada variabel mitigasi bencana alam yaitu 0,00. Hal ini menjadi permasalahan yang urgen, karena letak Desa Mekarsari berdekatan dengan gunung aktif, selain itu rawan banjir dan longsor. Sehingga program mitigasi bencana alam menjadi program yang dapat dipertimbangkan oleh pengelola zakat untuk Desa Mekarsari.

\section{Dimensi Dakwah}

Hasil perhitungan IDZ menunjukan nilai dimensi dakwah Desa Mekarsari menunjukan kondisi baik, sehingga tidak dipriritaskan untuk dibantu. Berikut hasil perhitungan dimensi, indeks variabel dan indeks indikator dimensi dakwah:

Tabel 1.5 Dimensi, Variable dan Indikator Indeks Dimensi Dakwah

\begin{tabular}{|c|c|c|c|c|c|}
\hline Dimensi & $\begin{array}{c}\text { Index } \\
\text { Dimensi }\end{array}$ & Variabel & $\begin{array}{c}\text { Index } \\
\text { Variabel }\end{array}$ & Indikator & $\begin{array}{c}\text { Index } \\
\text { Indikator }\end{array}$ \\
\hline \multirow{8}{*}{ Dakwah } & \multirow{8}{*}{0,68} & Tersedianya & \multirow{3}{*}{0,9225} & Ketersediaan Masjid & 0,75 \\
\hline & & Sarana \& & & Akses Ke Masjid & 1,00 \\
\hline & & $\begin{array}{l}\text { Pendamping } \\
\text { Keagamaan }\end{array}$ & & $\begin{array}{c}\text { Terdapat Pendamping } \\
\text { Keagamaan }\end{array}$ & 1,00 \\
\hline & & $\begin{array}{c}\text { Tingkat } \\
\text { Pengetahuan }\end{array}$ & \multirow{2}{*}{0,48} & $\begin{array}{c}\text { Tingkat Literasi Al-Qur'an } \\
\text { Masyarakat }\end{array}$ & 0,75 \\
\hline & & $\begin{array}{c}\text { Agama } \\
\text { Masyarakat }\end{array}$ & & $\begin{array}{c}\text { Kesadaran Masyarakat untuk } \\
\text { Berzakat dan Berinfak }\end{array}$ & 0,25 \\
\hline & & Tingkat & \multirow{3}{*}{0,63} & Kegiatan Rutin Keagamaan & 1,00 \\
\hline & & $\begin{array}{c}\text { Aktifitas } \\
\text { Keagamaan }\end{array}$ & & $\begin{array}{c}\text { Partisipasi Shalat Jama'ah } 5 \\
\text { Waktu }\end{array}$ & 0,25 \\
\hline & & $\begin{array}{c}\text { dan } \\
\text { Partisipasi } \\
\text { Masyarakat }\end{array}$ & & $\begin{array}{c}\text { Partisipasi Kegiatan Rutin } \\
\text { Keagamaan }\end{array}$ & 0,75 \\
\hline
\end{tabular}

Sumber: Data Primer diolah (2018)

Berdasarkan tabel 1.5 menunjukan kondisi Desa Mekarsri pada dimensi dakwah baik. Hal tersebut secara signifikan dipengaruhi ketersediaan sarana dan pendamping keagamaan, yang notabene lingkungan Desa Mekarsari terdapat pondok pesantren dan pendamping keagamaan yang cukup banyak. Sehingga disetiap rukun warga terdapat majelis ta'lim yang diikuti oleh warga Desa Mekarsari. Dengan demikian, 
program yang berkaitan dengan dimensi dakwah kurang diprioritaskan untuk dibantu dana zakat, meskipun nilai kesadaran masyarakat untuk berzakat dan berinfak memiliki nilai yang rendah yaitu 0.25 .

\section{KESIMPULAN}

Hasil perhitungan IDZ yang peneliti lakukan di Desa Mekarsari, dapat disimpulkan bahwa Desa Mekarsari layak menerima bantuan program zakat community development dengan nilai indeks desa zakat 0,55. Program yang direkomendasikan untuk Desa Mekarsari adalah peningkatan ekonomi melalui pengembangan produk unggulan yang potensial dan penggalakan pegiat ekonomi kreatif pada dimensi ekonomi, juga dimensi sosial dan kemanusiaan yaitu program mitigasi bencana bagi warga Desa Mekarsari Kabupaten Garut.

\section{PUSTAKA ACUAN}

Badan Pusat Statistik Provinsi Jawa Barat. Persentase Penduduk Miskin Menurut Kabupaten/ Kota Tahun 2012-2016. 8 Maret 2018. https://jabar.bps.go.id/statictable/2016/10/13/122/persentasependudukmiskin-menurut-kabupaten-kota-di-jawa-barat-persen-20022016.html

Beik, Irfan Syauqi, and Caesar Pratama. Zakat Impact on Poverty and Welfare of Mustahik: A CIBEST Model Approach. AFEBI Islamic Finance and Economic Review 1, no. 01. http://journal.afebi.org/index.php/aifer/article/view/16/7. (2016)

Beik, Irfan Syauqi, and Laily Dwi Arsyianti. 2016. "Measuring zakat impact on poverty and welfare using CIBEST Model." Journal of Islamic Monetary Economics and Finance 1, no. 2: 141-160.http://jimfbi.org/index.php/IIMF/article/view/524/508.

Farikhatusholikhah, Tanti Novianti and Khalifah Muhamad Ali. Implementation of the Zakat Village Index to Support a Zakat Community Development Program in Bedono Village, Demak District. International Journal of Zakat | ISSN: 25482335 | Vol. 3 (3) (2018). https://ijazbaznas.com/index.php/journal/article/view/93 
Elis Nurhasanah: Feasibility Study Program...

Jebrin, Ali Hadi. The Theoretical Strategic Approach in the Feasibility Study. Journal of Economics, Management and Trade: 14. http://www.journalrepository.org/media/journals/JEMT 66/2017/Sep/Jebrin 1922017JEMT36268.pdf

Kemenag RI Dirjen Bimbingan Masyarakat Islam Direktorat Pemberdayaan Zakat. 2013. Zakat community development Model Pengembangan Zakat.

Khairunnajah. Irfan Syauqi Beik and Bagus Sartono. Proposing a Zakat Empowerment Program Using IDZ: Case from Cemplang Village, Bogor, Indonesia. International Journal of Zakat, 4(1), 45-54. (2018).https://www.ijazbaznas.com/index.php/journal/article/view/139

Nurzaman Muhammad Soleh. Zakat and Human Development: an Empirical analysis on poverty allevation in Jakarta, Indonesia.Center for Isamic Economics and Finance, Qatar faculty of Islamic studies, Qatar foundation. P (2010):1-26. (2018)

Purnomo, Aldy Rochmat, Riawan dan La Ode Sugianto. Studi Kelayakan Bisnis UNMUH Ponorogo Press. (2017)

Pusat Kajian Strategis. Indeks Desa Zakat. (Jakarta: Center of Strategic Studies BAZNAS 2017)

Sadeq, AbulHasan M. Waqf, perpetual charity and poverty alleviation. International Journal of Social Economics 29, no. 1/2: 135-151. (2002).https://www.emerald.com/insight/content/doi/10.1108/0306829021 $\underline{0413038 / \mathrm{full} / \mathrm{html}}$

Sumantri, Rinol. Efektifitas dana zakat pada mustahik zakat community development sumatera selatan dengan pendekatan CIBEST. I-ECONOMICS: A Research Journal on Islamic Economics 3, no. 2: 209-234. http://jurnal.radenfatah.ac.id/index.php/ieconomics/article/view/1688

Utami, Siti Halida, and Irsyad Lubis. Pengaruh Pendayagunaan Zakat Produktif Terhadap Pemberdayaan Mustahiq di Kota Medan. Ekonomi dan Keuangan 2, no. 6. (2014) https://jurnal.usu.ac.id/index.php/edk/article/view/11688/5048. 
Islamiconomic: Jurnal Ekonomi Islam Vol.10 No.2 Juli - Desember 2019 